\title{
O FUTURO DA REPRESENTAÇÃO POLÍTICA DEMOCRÁTICA [André Freire (org.), 2015, Lisboa, Nova Vega]
}

\author{
Pedro Carvalhais de Abreu Matos \\ Departamento da Sociedade de Informação da Fundação para a Ciência e a Tecnologia, I.P., \\ Lisboa, Portugal
}

O conjunto de ensaios reunidos na obra O Futuro da Representação Política Democrática, organizados por André Freire - a quem coube também a responsabilidade pela Introdução e ainda o capítulo I - e publicado pela Nova Vega, tem em conceitos como "democracia" e "representação" a base de sustentação para traçar alguns cenários possíveis ou que é expectável observar nas democracias num futuro próximo. Partindo daquele que parece ser o fenómeno que começa a adquirir alguma presença recorrente nos estudos políticos, a crescente desconfiança dos cidadãos nas instituições, não só nas "não democráticas" mas também nas "democráticas", e um consequente afastamento entre governantes e governados que nesta obra adquire uma relação de representantes e representados, este trabalho coletivo pretende em diversos níveis - social e político, nacional, europeu e global - abordar a evolução histórica até à atual situação de incerteza das democracias representativas e ainda propor aos leitores reflexões sobre cenários futuros em cada um dos temas abordados. A concretização deste exercício, que não ignora o facto de a sua génese conceptual assentar na discussão teórica nem sempre de consenso alargado entre estudiosos, sai reforçada, à partida, com dois aspetos determinantes: o primeiro, para além da capacidade reconhecida aos investigadores que assinam estes ensaios, é a longa e larga experiência profissional de facto de alguns deles; o segundo, a transversal tomada em consideração das características introduzidas pela mais recente crise económica e financeira ao nível mundial, que se assume como tendo tido o seu início em 2007 nos Estados Unidos da América alastrando-se, a partir de 2008, até ao continente europeu, com sério impacto nos regimes democráticos representativos.

O livro encontra-se dividido em sete capítulos. O capítulo 1, elaborado por André Freire, discorre sobre a delegação de poderes dos representados nos representantes, partindo das transformações introduzidas pelas "vagas de democratização", sem omitir o sempre presente e atual perigo de involução dos regimes democráticos, nomeadamente com a evidência do colapso de algumas democracias já no século XXI. Assente num vasto conjunto de teóricos contemporâneos - como Norberto Bobbio (1909-2004), Robert Dahl (1915-2014), Peter Mair (1951-2011), Wolfgang Merkel (1952-) ou Giovanni Sartori (1924-) entre muitos outros, sem esquecer autores clássicos como Edmund Burke (1729-1797) - um dos principais pontos para o qual André Freire chama a atenção na sua tentativa de traçar o "futuro da democracia representativa" é a dicotomia presente no entendimento do mandato do representante, nomeadamente sobre a visão do mandato delegado, onde "do legislador é esperado que limite a sua 
ação às instruções explícitas dos seus constituintes, servindo como uma espécie de veículo passivo dos sentimentos destes" (p. 20), em contraposição com o mandato não imperativo onde "uma vez selecionado, o (bom) representante usa o seu juízo e a sua consciência como a ultima ratio para as suas decisões como legislador, com base nas regras da decisão deliberativa" (p. 20). Elaborando padrões evolutivos da representação e apresentando modelos de democracia para chegar a hipotéticos futuros modelos de democracia, no plano nacional e internacional, Freire sintetiza de forma bastante clara as principais características decorrentes das alterações nos regimes democráticos com a predominância do "modelo de capitalismo desregulado e financeiro", a partir do final da década de 1970, em detrimento do "modelo de capitalismo keynesiano de bem-estar social". Destas transformações salientam-se duas de grande impacto na relação representante vs. representado: uma acentuação da baixa participação nos atos eleitorais, acompanhada de uma elevada exclusão social, e também um maior enfraquecimento ao nível da "responsabilização horizontal (e vertical)", tanto ao nível do poder executivo (governos) como do poder legislativo (parlamentos).

O capítulo 2, da responsabilidade de Cristina Leston-Bandeira e Tiago Tibúrcio, debruça-se sobre "o futuro da representação parlamentar" retomando o multifacetado conceito de "representação", nomeadamente sobre o papel que os parlamentos desempenham, ou poderão vir a desempenhar, na relação entre os representantes e os representados. Considerando os diversos interesses dos eleitores, atualmente mais alargados do que antes, os parlamentos enfrentam hoje novos desafios com novos instrumentos na relação entre a instituição e o cidadão, $o$ que, segundo os autores, representa um estado de transição entre o modelo de "representação como delegação e o da representação como uma relação" (p. 88). A partir deste cenário, que resulta de uma abertura dos parlamentos aos cidadãos e pela integração de modos de democracia participativa, que passam também pela implementação de ferramentas como petições, ou de processos de iniciativa legislativa dos cidadãos, ainda que deles já existam algumas evidências, não é possível aferir as consequências do seu alargamento que, como Cristina Leston-Bandeira e Tiago Tibúrcio bem salientam, terá necessariamente impacto no sistema democrático representativo e concomitantemente na existência dos próprios parlamentos.

Ao "futuro dos partidos na representação política", de Marco Lisi, ficou reservado o capítulo 3. Neste texto, o autor começa por destacar a perceção por parte dos cidadãos de uma falta de sentido de representação nos partidos políticos. Sustentado num vasto conjunto de trabalhos estatísticos, Marco Lisi destaca o falhanço dos partidos no que respeita às suas funções essenciais "enquanto agentes de participação e mobilização". Um aspeto interessante neste ensaio e que é revelador da atual situação é o facto de tomar em consideração inquéritos pós-eleitorais, uma característica que em muitos estudos em torno desta temática é desconsiderada ou nem sequer abordada. Neste campo, o autor salienta "a drástica diminuição dos que se sentem muito próximos de algum partido: nas eleições de 2002 havia $32 \%$ de eleitores com fortes identidades partidárias, enquanto nas eleições de 2011 esta percentagem é de apenas $3 \% "$ (p. 97). Referindo ainda que a crise de representação política, para além da modernização verificada nos sistemas partidário, social e 
económico, decorre também do modo de funcionamento interno dos partidos, nomeadamente sobre o peso que têm os seus filiados, o autor deixa alguns alertas decorrentes da falta de apoio ao regime democrático - com uma difícil implementação de medidas em linha com as preferências dos eleitores - e uma eventual transferência de poderes para as instituições não democráticas.

Relativamente ao capítulo 4, com o tema do "futuro do sindicalismo na representação sociopolítica", poderá à partida parecer ao leitor que se trata de um ensaio algo deslocado do alinhamento proposto nesta obra coletiva. No entanto, Elísio Estanque, Hermes Augusto Costa e Manuel Carvalho da Silva, traçando a origem e o percurso do sindicalismo, não só em Portugal, assim como os desafios que se lhe colocam, recentram a discussão na importância da representação sindical, seja nos processos de decisão como nos processos das relações sociais. Sustentam os autores que "a defesa de um projeto de aprofundamento dos valores intrínsecos à vida democrática das sociedades avançadas, onde os princípios da igualdade, dos direitos humanos, do progresso e da justiça social são pedras de toque fundamentais, continuará a servir de modelo pelo qual se batem as lutas sociais e sindicais do nosso tempo" (p. 137).

O ensaio mais curto deste livro pertence a Britta Baumgarten, capítulo 5, dedicado ao "futuro dos movimentos sociais na representação sociopolítica". Também aqui retomando o conceito de representação (política), a autora destaca a importância dos movimentos sociais na participação em processos de decisão e no envolvimento político - dá como exemplo os orçamentos participativos e sua rápida disseminação por diversos regimes democráticos, ainda que utilizados apenas ao nível político local - e os desafios que lhes são impostos pela globalização. Esta abordagem adquire uma outra dimensão na medida em que, segundo a mesma, "os desempregados e os trabalhadores precários não têm representação política na sociedade moderna, uma vez que os sindicatos representam principalmente os interesses dos trabalhadores regulares. $E$ os deputados são principalmente das classes média e alta. Os grupos mais vulneráveis então estão sub-representados na política institucional" (p. 149). Entre vários cenários possíveis definidos por Baumgarten, não será por demais aluir à referida importância que os movimentos sociais venham a ter na fundação de novos partidos e no impacto destes na política institucionalizada.

Com o capítulo 6, sobre o "futuro da construção europeia na era da globalização, por José Pedro Teixeira Fernandes, é abordado neste livro o plano internacional da representação democrática. Revisitando a teoria da representação política e o processo de construção da atual União Europeia, assente nos estudos de teóricos de referência como Giandomenico Majone (1932-), Peter Mair ou Andrew Moravcsik (1957-), entre outros, o autor traz à discussão o "teorema da impossibilidade", também conhecido com o "trilema da economia mundial" de Dani Rodrik (1957-), que apresenta uma aparente incompatibilidade de, no atual paradigma de globalização, conseguir conciliar simultaneamente as suas três principais características: o aprofundamento da integração económica, o estado-nação e a democracia (políticas democráticas). Considera José Pedro Teixeira Fernandes que "apesar dos impactos da globalização e outros, resulta inquestionavelmente que o modelo usado 
na construção europeia tem levado, e continua a levar, a um estreitamento da margem de manobra política, bem como das opções reais para os partidos e cidadãos no plano nacional" (p. 171), preconizando dois cenários possíveis: (1) o de uma construção europeia baseada nas teorias federalistas; (2) o do aprofundamento da construção europeia assente na visão tecnocrática mas com uma maior separação de poderes. Neste ponto, o leitor mais familiarizado com a história da integração europeia poder-se-á sentir tentado a colocar numa perspetiva comparada aquelas que foram as discussões e posições sobre o modelo de integração após a Segunda Guerra Mundial e os cenários futuros agora propostos.

O último capítulo foca-se no "futuro da governação democrática na era da globalização: o triunfo ideológico de uma força de governo ultrapassada", e é da autoria de Emmanouil Tsatsanis. Tendo como pressuposto o fim do enclausuramento dos estados e a facilidade de disseminação e "triunfo da democracia" num mundo globalizado, o autor divide em duas categorias as previsões sobre o futuro da governação democrática: as que continuam a advogar a expansão mundial da democracia e as que encontram um esvaziamento das democracias na era da globalização. Estas categorias estão divididas de acordo com a perspetiva e relação mais otimista ou pessimista de cada um dos seus defensores. Face à crescente complexidade introduzida pelos diversos níveis de governação ao nível global, tomando como exemplo o multinível em prática na União Europeia, neste ensaio são abordadas algumas das fragilidades patentes na relação entre representantes e representados, i.e. a incapacidade de uma resposta adequada às exigências e vontades dos cidadãos por parte dos deputados e partidos políticos, uma situação que pode conduzir a uma reinterpretação por parte dos representados sobre o modelo democrático mais desejado para corresponder às suas demandas. Alertando para o facto de os modelos orientais, especialmente o russo e chinês, serem já referências para democracias emergentes, Tsatsanis conclui que "a democracia representativa está em crise. Esta crise democrática não começou com a atual crise económica, mas certamente tem piorado por causa disso" (p. 195).

Em suma, com os possíveis cenários futuros propostos pelos autores, esta obra poderá vir a ser mais um importante contributo para a concretização de algumas das promessas da democracia que Bobbio definiu como incumpridas. O Futuro da Representação Política Democrática reúne um conjunto de textos cuja leitura e estudo devem interessar não só a académicos, mas também aos próprios dirigentes e decisores políticos, bem como aos cidadãos que inevitavelmente transferem para os anteriores a tomada de decisão. Esta transversalidade no putativo público-alvo é conseguida pela forma como os textos estão estruturados e escritos, i.e. não têm a muito habitual característica neste tipo de estudos que é a da pretensão de uma atenção, compreensão e crítica apenas por pares.

Pedro Carvalhais de Abreu Matos. Técnico superior no Departamento da Sociedade de Informação da Fundação para a Ciência e a Tecnologia, I.P., Lisboa, Portugal.E-mail: pca2002@gmail.com 